\title{
OTIOLTOMTS
}

Revista d'economia, empresa i societat

Dossier sobre economia col-laborativa (I)

Economies de plataforma i negocis col-laboratius

Coordinador: Joan Torrent-Sellens

\section{Fixació de preus en mercats digitals bilaterals entre iguals: el cas d'Airbnb a Barcelona}

\author{
Josep Lladós-Masllorens \\ Professor agregat dels Estudis d'Economia i Empresa (UOC) \\ Antoni Meseguer-Artola \\ Professor agregat dels Estudis d'Economia i Empresa (UOC) \\ Inma Rodríguez-Ardura \\ Professora agregada dels Estudis d'Economia i Empresa (UOC)
}

RESUM Les plataformes digitals que faciliten el contacte directe entre proveïdors i consumidors de serveis d'allotjament han transformat profundament el mercat turístic. En aquests mercats bilaterals, les estratègies de fixació de preus esdevenen crucials per a la creació de valor malgrat que, a diferència dels mercats digitals convencionals, els preus es determinen per proveïdors de serveis que no són professionals i que, alhora, també actuen com a consumidors.

Airbnb en representa el cas de més èxit, pel que fa al volum i diversitat d'ofertes residencials d'ús turístic. A les extenses llistes d'habitatges publicades a Airbnb, conviuen els allotjaments oferts per consumidors finals amb l'oferta comercial d'habitatges procedent d'intermediaris i operadors professionals, els quals aprofiten aquest mercat digital entre iguals (peer-to-peer digital marketplace) per ampliar les seves oportunitats de negoci. La major part d'estudis previs envers la formació de preus en aquesta plataforma no até a diferenciar ambdós col·lectius. El nostre estudi vol contribuir a reduir aquesta escletxa tot focalitzant l'anàlisi exclusivament en les transaccions entre iguals en el mercat bilateral digital d'Airbnb a la ciutat de Barcelona.

Els resultats obtinguts ressalten el rol determinant de les preferències dels consumidors per les qualitats funcionals dels allotjaments. També mostren com el sistema d'avaluacions online i el comportament d'altres consumidors influeixen en la determinació dels preus.

PARAULES CLAU Airbnb; mercats digitals; comportament consumidors; peer-to-peer; fixació de preus 


\title{
Pricing in peer-to-peer and two-sided digital marketplaces: Airbnb in Barcelona
}

\begin{abstract}
Digital platforms are changing the way in which suppliers and consumers of accommodation services interact, deeply transforming the tourism market. In these peer-to-peer and twosided digital marketplaces, pricing strategies become crucial for value generation, yet in contrast to conventional digital marketplaces, prices are set by non-professional vendors who are also consumers.

Airbnb is the most successful case of sharing economy-based accommodation rental, providing a vast and diverse range of places for tourists to stay in. In this digital marketplace, final consumers compete with professional hosts, looking for new business opportunities. Previous studies on pricing have not made a distinction between both groups. Our investigation aims to reduce this gap by focusing just on peer-to-peer transactions. We use a large dataset covering accommodation listed by non-professional hosts in Barcelona.

The paper offers evidence that higher accommodation prices are best explained by consumers' preference for the intrinsic functional qualities of the value proposition. The systematic interaction of value and volume of online reviews and pricing strategies of close players can also produce a crucial impact on pricing.
\end{abstract}

KEYWORDS Airbnb; digital marketplaces; consumer behavior; peer-to-peer; pricing

\section{Introducció i objectius}

Als mercats digitals peer-to-peer, consumidors i proveïdors interaccionen i s'intercanvien rols en un procés de creació conjunta de valor (Kumar i Reinartz, 2016). Els proveïdors de serveis en aquests mercats bilaterals pro-porcionen informació sobre la seva proposta de valor, es relacionen amb els potencials consumidors, fixen preus i s'impliquen en relacions d'intercanvi monetari de la mateixa manera que ho fan els professionals en els mercats convencionals. Alhora, els consumidors contribueixen a un ús més eficient dels béns o serveis oferts, ja que els contracten i fan servir en moments en què estaven sent infrautilitzats (Liang et al., 2018).

Probablement el mercat digital bilateral més rellevant per a la industria de l'allotjament turístic sigui Airbnb. La plataforma acull una oferta residencial molt àmplia i diversa en més de 200 països i 100.000 ciutats, la qual proveeix d'allotjament diari a més de 2 milions de persones (Airbnb Newsroom, 2020).

La ràpida expansió d'Airbnb ha despertat l'interès d'empreses i interme-diaris professionals, que utilitzen la plataforma per ampliar les seves oportu-nitats de negoci i optimitzar la rendibilitat de la seva cartera immobiliària. Com a resultat, el mercat digital cada cop més allotja activitats mercantils que no s'ajusten necessàriament al model de consum collaboratiu (Ke, 2017).

A diferència de la industria hotelera tradicional, Airbnb ni disposa d'allotjaments de propietat ni tampoc en gestiona. Només permet als seus consumidors compartir els seus habitatges amb turistes, proporcionant un servei més informal i econòmic que el d'un hotel (Kavadias et al., 2016). En contraposició amb els processos de consum tradicionals, en què un producte és generalment utilitzat per un únic consumidor, els allotjaments a Airbnb poden ser consumits per molts viatgers per una estada curta. D'aquesta ma-nera, es mobilitzen recursos ociosos per adaptar-se millor a les necessitats dels consumidors (Henten i Windekilde, 2016). Alhora, mitjançant l'accés a un allotjament privat, els turistes tenen més oportunitats de relacionar-se amb els residents locals i gaudir d'una experiència única i més autèntica. Totes dues parts, propietaris d'habitatges i viatgers, 
interactuen socialment i col-laboren en la generació de valor (Eisenmann et al., 2006; Habibi, 2019). En aquest mercat bilateral, el valor emergeix tant de la interacció directa entre amfitrió i hoste com també de la implicació conjunta de la xarxa d'usuaris (Dellaert, 2019; Ramaswamy i Ozcan, 2018).

La fixació de preus és un dels components més crítics en aquest procés de generació de valor als mercats digitals: determina els ingressos obtinguts pels usuaris de la plataforma que proporcionen accés als seus habitatges i influeix en la presa de decisions dels consumidors potencials. No és estrany que en els darrers anys emergeixin investigacions sobre aquest àmbit (Guttentag (2019) sintetitza els principals resultats d'aquesta investigació).

Tot i amb això, en aquests estudis previs s'inclouen les propietats ofertes per operadors professionals que són gestionades amb propòsits purament comercials i que no encaixen gaire bé amb les característiques intrínseques del model d'economia colllaborativa. Significativament, alguns estudis apunten que els usuaris habituals (que utilitzen la plataforma amb fins no lucratius) semblen mostrar estratègies de preus diferents, menys dinàmiques i menys remuneradores que les empreses i intermediaris amb qui competeixen a la plataforma ( $\mathrm{Li}$ et al., 2019).

Probablement, aquest sigui el dèficit més important de la recerca efectuada fins al moment envers Airbnb: la poca atenció atorgada al procés de formació de preus en el context de relacions purament entre iguals, és a dir, entre oferents ocasionals que en el futur també poden esdevenir consumidors dels serveis d'allotjament. La nostra recerca pretén atendre aquesta necessitat, focalitzant-se estrictament en els mecanismes que determinen la fixació de preus en les transaccions entre iguals.

De fet, la presència d'agents immobiliaris i intermediaris turístics que gestionen la seva oferta com a part del seu negoci de lloguer residencial està creixent substancialment en els darrers anys (Kwok i Xie, 2019). Els estudis previs sobre la determinació de preus a la plataforma són, doncs, difícilment generalitzables al context de l'economia col·laborativa.

Aquest biaix d'interpretació es fa més evident si tenim en compte que els consumidors habituals i els operadors professionals operen dins Airbnb amb objectius, disponibilitat de recursos i experteses molt diferents. Les decisions de preus poden ser particularment complexes per als usuaris ocasionals de la plataforma perquè, en la mesura que Airbnb permet als amfitrions que lloguen el seu habitatge un marge discrecional significatiu a l'hora de determinar els preus (Newlands et al., 2018), els consumidors habituals han de fer front al repte d'optimitzar el seu ingrés, satisfer les necessitats dels usuaris potencials i competir amb un nombre creixent d'habitatges oferts a la plataforma (Gibbs et al., 2018). En conseqüència, les estratègies de preus dels consumidors que ofereixen allotjament (que són precisament els oferents que generen les dinàmiques més properes a les d'una economia col·laborativa) podrien estar afectades per problemes d'excés de confiança, una gestió inadequada del risc o la manca d'expertesa, sobretot quan es comparen amb les estratègies dels operadors professionals que actuen a la plataforma (Li et al., 2016).

\section{Dades i metodologia}

La teoria de la demanda hedònica ofereix un esquema d'anàlisi per entendre les estratègies de preus en els mercats digitals bilaterals, com és el cas d'Airbnb (Lancaster, 1966). D'acord amb aquest marc conceptual, a cada atribut d'un bé o servei determinat se li pot assignar un preu que mostri tant la valoració que fan els consumidors d'aquest element com la seva voluntat de pagar una prima per gaudir del seu ús o consum (Rosen, 1974). Ja que les activitats turístiques acostumen a proveir el mercat de productes heterogenis, aquesta aproximació teòrica s'ha utilitzat profusament en recerques prèvies sobre aquest àmbit (Cai et al., 2019; Gibbs et al., 2018; Chen i Xie, 2017; Teubner et al., 2017).

Conseqüentment, en la nostra anàlisi utilitzem un model de preus hedònic (MPH). Atès que aquest model se sustenta en la hipòtesi subjacent que el preu d'un producte depèn dels diferents components que creen valor afegit (Fleischer, 2012; Schamel, 2012; Ziet el al., 2008), les funcions hedòniques descomponen el preu del pro- 
ducte en els seus atributs o qualitats, que alhora es poden agrupar en funció de les seves característiques (Sopranzetti, 2010).

En particular, adoptem el model additiu lineal següent:

Preu $=c+\beta X+\varepsilon$

on Preu és el vector dels preus publicats a Airbnb, c és el vector constant, $\beta$ és el vector dels coeficients, $X$ és la matriu de tots els atributs i $\varepsilon$ és el terme d'error.

L'ampli i divers conjunt d'atributs que els consumidors utilitzen com a indicadors del valor d'un bé o servei pot ser classificat com a intrínsec o extrínsec (Richardson, 1994; Olson et al., 1972). Els atributs intrínsecs reflecteixen les qualitats i característiques essencials de l'objecte de consum, que són aquelles que determinen la seva funcionalitat (Diallo et al., 2018; Alba et al., 1987). Per la seva part, els atributs extrínsecs estan mediats per les relacions de mercat i sovint fan referència al posicionament de la marca, com ara la imatge i la reputació del venedor o les percepcions que es formen els consumidors (Choi et al., 2018). A diferència dels atributs intrínsecs de la proposta de valor, els quals són tangibles i fàcilment quantificables, les qualitats extrínseques són intangibles i abstractes i, tot i estar relacionades amb el bé o servei, no en són parts inherents (Devlin, 2011).

Partint d'aquesta aproximació, també poden diferenciar entre determinants intrínsecs i extrínsecs dels preus a Airbnb. Els primers fan referència a la funcionalitat de la proposta de valor i les qualitats objectives de l'allotjament que són inherents al servei que es vol consumir (Abrate i Viglia, 2016; Rao, 1984), mentre que els segons estan relacionats subjectivament amb el valor percebut de l'allotjament per part dels potencials consumidors i són definits essencialment per les relacions i interaccions a la plataforma digital. Aquestes interaccions es realitzen sobretot entre amfitrions i viatgers (Chen i Xie, 2017) i és per mitjà d'aquestes com es produeix la cocreació de valor (Sundararajan, 2016).

La dimensió, la localització física, la tipologia i els serveis i comoditats de l'allotjament permeten als consumidors avaluar el valor funcional o utilitari d'una proposta, incloent si l'habitatge és espaiós, si pot encabir còmodament el grup familiar, quin és el nivell de privacitat que proporciona o si l'estada esdevindrà més confortable (Cai et al., 2019; Chen i Xie, 2017; Wang i Nicolau, 2017). De la mateixa manera, l'heterogeneïtat de les polítiques d'allotjament per part del propietari de l'immoble també pot comportar diferències en els preus. És el que succeeix, per exemple, amb les polítiques que donen flexibilitat en la cancel·lació, les que requereixen un nombre mínim de nits d'estada o la inclusió del servei de neteja, entre d'altres (Benítez-Aurioles, 2018; Gibbs et al., 2018; Kakar et al., 2018).

Els atributs extrínsecs resulten de les interaccions existents al mercat bilateral. La reputació, que desvetlla atributs de qualitat inobservables abans de la transacció, pot incidir sobre el preu (Shapiro, 1983; Klein i Leffler, 1981). De fet, aquest rol de la reputació pot ser encara més important a causa de les incerteses que generen les decisions de consum de productes d'experiència als mercats digitals (Meseguer-Artola i Rodríguez-Ardura, 2015; Dimoka et al., 2012). Els hostes poden calibrar, a priori, els esforços dels amfitrions per satisfer les seves necessitats per mitjà de diferents indicadors, com la verificació de la seva identitat per Airbnb (Ert et al., 2016), l'obtenció d'una acreditació de superhost (Chen i Xie, 2017) o la seva experiència a la plataforma digital (PérezSánchez et al., 2018; Teubner et al., 2017).

De la mateixa manera, un allotjament pot assolir una bona reputació mitjançant el sistema de ràtings i ressenyes elaborades pels consumidors anteriors. Els consumidors potencials tenen en consideració aquestes informacions en la seva presa de decisions, sobretot quan les avaluacions provenen dels seus iguals (Ye et al., 2012; Cui et al., 2012). Aquesta valoració també pot ser influïda pel nombre d'opinions prèvies envers l'habitatge, la qual cosa dona peu al fet que hi hagi un efecte d'interacció entre el volum i valor mitjà de les avaluacions atorgades pels consumidors anteriors (Maslowska et al., 2017; Kostyra et al., 2016; Etzion i Awad, 2007).

Finalment, la fixació de preus també pot estar condicionada per la competència directa d'altres allotjaments situats als voltants (Cai et al., 2019; Chen i Xie, 2017, Becerra et al., 2013). Com més intensa sigui la competència i més estigui basada en els preus, més dificultats tindran els oferents d'allotjament per diferenciar el valor de la seva proposta, donant lloc a l'emergència de dependències espacials que poden influir en el procés de fixació de preus.

A la taula 1 es mostren les quinze variables incloses al model, agrupades en sis blocs diferents. 
Taula 1. Grups i descripció de variables

\begin{tabular}{|c|c|c|}
\hline Grup & Variable & Descripció \\
\hline Variable dependiente & Price & Listed preice of the accommodation (\$) \\
\hline \multirow{4}{*}{$\begin{array}{l}\text { Funcionalitats } \\
\text { bàsiques }\end{array}$} & Size & Number of guests \\
\hline & Bathrooms & Number of bathrooms \\
\hline & EntireUnit & Dichotomic variable: 1 = entire home/apt., 0 = not entire home/apt. \\
\hline & AmenitiesIndex & $\begin{array}{l}\text { Additive index: Family Friendly + Breakfast + Parking + Wi-Fi+ CableTV + Pool + Elevator } \\
+ \text { Gym + Doorman }\end{array}$ \\
\hline $\begin{array}{l}\text { Flexibilitat política } \\
\text { allotjament }\end{array}$ & RentalPolicy & $\begin{array}{l}\text { Additive index: CancellationFlexibility (strict/very strict) + MinimumNights }(>1)+ \\
\text { CleaningFee }(<0)+\text { GuestPhoto + GuestPhone }\end{array}$ \\
\hline \multirow[t]{2}{*}{ Localització } & Location & $\begin{array}{l}\text { Mean (Haversine) distance to Güell Park }(41.413525,2.152077) \text {; Milà House }(41.395183 \text {, } \\
\text { 2.161801); Sagrada Família Church }(41.404065,2.174648) \text {; Batlló House }(41.391737 \text {, } \\
\text { 2.164962); Picasso Museum }(41.385167,2.180831) \text {; FCB Museum }(41.380218, \\
\text { 2.120824); Born Cultural Center }(41.385661,2.183570)\end{array}$ \\
\hline & HostVerified & Dichotomic variable: $1=$ host verified by Airbnb, $0=$ not verified \\
\hline \multirow{3}{*}{$\begin{array}{l}\text { Característiques } \\
\text { amfitrió }\end{array}$} & Superhost & Dichotomic variable: $1=$ host is a superhost, $0=$ not a superhost \\
\hline & HostExperience & Number of months since host's appearance in the Airbnb listing \\
\hline & ReviewValence_PCA & $\begin{array}{l}\text { First component scores from the PCA with variables: } \\
\text { review_scores_accuracy; review_scores_cleanliness; review_scores_check-in; review_ } \\
\text { scores_communication; review_scores_location; review_scores_value }\end{array}$ \\
\hline \multirow{2}{*}{ Valoracions i ratings } & ReviewsVolume & Number of reviews \\
\hline & Velence_x_Volume & Number of reviews multiplied by ReviewValence_PCA \\
\hline \multirow{2}{*}{ Competència } & CompetitionIntensity & Number of competitors with same room type in the neighborhood \\
\hline & CompetitionPrice & Nearby competitors' price per guest mean value \\
\hline
\end{tabular}

Font: Elaboració pròpia a partir de les dades procedents de http://insideairbnb.com/

A fi de millorar la consistència del conjunt de la base de dades, no es van considerar tampoc aquells allotjaments en els quals el nombre de convidats superava en més de dues vegades el nombre de llits informats. També es va utilitzar la regla del rang interquartílic per definir el preu variable per hoste (i així evitar valors atípics). A més, es van eliminar tots els casos amb valors omesos. El conjunt de dades final contenia 6.184 observacions, cosa que representava un 30,3\% del total dels allotjaments d'Airbnb a Barcelona a la data de la recollida de dades.

Pel que fa a l'estimació del model, l'anàlisi d'autocorrelació va mostrar un valor del estadístic Durbin-Watson molt proper a dos $(1,99)$ i, per tant, es va descartar l'existència de problemes d'autocorrelació de primer ordre. Al test de White, el valor $p$ de l'estadística $N^{\star} R 2=2.223,06$ va ser 0,00 , el que suggereix que l'estimació del model tenia problemes d'heteroscedasticitat. Per tal de resoldre'ls, es van ajustar els errors estàndard utilitzant els coeficients de la matriu de covariàncies.

El resultat del model es mostra a la taula 2. Els factors d'inflació de la variància (VIF) estan per sota del valor crític de 10, fet que indica l'absència de problemes de multicol-linealitat. En general, l'ajust del model de preus hedònic és bo. Mesurat amb l'R2, el poder explicatiu de l'equació de regressió és elevat: el 59,7\% de la variació dels preus s'explica per les variables independents incloses en el model. L'MPH és globalment significatiu (estadística $F=651,28$, valor $p=0,00$ ) i la majoria de les variables explicatives són significatives. 
Taula 2. Resultats de la regressió lineal

\begin{tabular}{|c|c|c|c|c|c|c|}
\hline Variable & Coefficient & $\begin{array}{c}\text { Standardized } \\
\text { Coefficient }\end{array}$ & Std. Error & $t$-Statistic & $p$-value & VF \\
\hline (Constant) & $-7,573$ & - & 3,682 & $-1,952$ & 0,051 & - \\
\hline Size & 16,288 & 0,563 & 0,761 & 21,413 & 0,000 & 3,183 \\
\hline Bathrooms & 14,242 & 0,13 & 1,806 & 7,885 & 0,000 & 1,052 \\
\hline EntireUnit & 14,957 & 0,143 & 1,692 & 8,839 & 0,000 & 2,840 \\
\hline AmenitiesIndex & 2,401 & 0,058 & 0,434 & 5,529 & 0,000 & 1,308 \\
\hline RentalPolicy & 0,925 & 0,02 & 0,416 & 2,223 & 0,026 & 1,199 \\
\hline Location & $-3,097$ & $-0,059$ & 0,516 & $-5,998$ & 0,000 & 1,550 \\
\hline HostVerified & 0,038 & 0,001 & 0,843 & 0,045 & 0,964 & 1,058 \\
\hline Superhost & 5,308 & 0,047 & 1,129 & 4,701 & 0,000 & 1,471 \\
\hline HostExperience & $-0,002$ & $-0,002$ & 0,005 & $-0,338$ & 0,736 & 1,024 \\
\hline ReviewValance_PCA & 0,165 & 0,003 & 0,495 & 0,334 & 0,739 & 1,181 \\
\hline ReviewsVolume & $-0,047$ & $-0,068$ & 0,008 & $-5,815$ & 0,000 & 1,799 \\
\hline Valence_ $x$ _Volume & 0,043 & 0,038 & 0,013 & 3,390 & 0,001 & 1,715 \\
\hline Competitionlntensity & 0,004 & 0,023 & 0,002 & 2,617 & 0,009 & 1,433 \\
\hline CompetitionPrice & 0,108 & 0,032 & 0,050 & 2,177 & 0,030 & 1,494 \\
\hline$R$-squared & 0,596 & & & & & \\
\hline Adjusted $R$-squared & 0,596 & & & & & \\
\hline F-statistic & 651,277 & & & & & \\
\hline Prob (F-statistic) & 0,000 & & & & & \\
\hline
\end{tabular}

Font: Elaboració pròpia a partir de les dades procedents de http://insideairbnb.com/

\section{Discussió dels resultats}

Les estratègies de preus en les transaccions entre operadors no professionals en el mercat digital bilateral d'Airbnb estan influïdes tant per les característiques funcionals dels allotjaments com també per aspectes que tenen a veure amb la interacció entre els consumidors de la plataforma. La dimensió de l'allotjament, els serveis proveïts i la privacitat que proporciona l'allotjament són els atributs més apreciats pels usuaris d'Airbnb; i una major utilitat percebuda es trasllada en preus també més elevats. L'oferta d'un conjunt ampli de serveis dissenyats per proporcionar als usuaris una estada més confortable, grata, propera i còmoda també influeix positivament en la determinació del preu del lloguer.

Les característiques de la política d'allotjament també es deixen sentir en la fixació de preus. Polítiques més estrictes no solament fan percebre als amfitrions que la seva propietat i parament de la llar estan millor protegits, sinó que també proporcionen un valor als hostes, que l'interpreten com un indicador d'un allotjament més ben equipat i d'una major implicació dels amfitrions en el servei.

La localització de l'habitatge també influeix de forma molt significativa en els nivells de preus. Les tarifes més elevades es troben als barris més cèntrics o més propers a les principals atraccions turístiques. Aquest resultat és plenament coincident amb el gruix de la literatura existent (Cai et al., 2019; Pérez-Sánchez et al., 2018; Gibbs et al., 2018; Teubner et al., 2017; Wang i Nicolau, 2017)

Tal com era previsible, els allotjaments oferts per un amfitrió amb l'estatus de superhost són reconeguts pels usuaris de la plataforma com d'un valor superior i, per tant, s'associen a una prima en el preu. De la mateixa manera que el sistema d'estrelles, categories i marques a la indústria hotelera, aquesta acreditació actua com a factor mitigador de riscos en la presa de decisions, proveint d'una informació rellevant i generadora de confiança envers els esforços de l'amfitrió a l'hora de satisfer les necessitats de l'hoste.

De la mateixa manera que s'ha observat en diverses ciutats alemanyes (Teubner et al., 2017), el fet que un amfitrió sigui verificat per Airbnb tampoc no es percep a Barcelona com un indicador de qualitat que meriti una millor remuneració. Aquest efecte no significatiu podria estar explicat per l'àmplia adopció del procediment de verificació entre els consumidors regulars.

Un altre resultat inesperat és que el nivell d'experiència de l'amfitrió no afecta els nivells de preus. Tot i que l'experiència pot contribuir a millorar la reputació de l'amfitrió i reforçar la confiança en el valor de l'allotjament, no 
dona lloc a primes de preu. Això es pot deure al fet que els hostes són conscients de la participació ocasional i informal de molts amfitrions, així que l'experiència acumulada a Airbnb els interessa poc.

El fet que les avaluacions dels allotjaments no tingui influència directa en el seu preu, probablement sigui conseqüència de la baixa variabilitat existent entre els valors assignats pels clients, i la gran preponderància de qualificacions altes (valor mitjà de 9,28). La capacitat de diferenciació esdevé, doncs, negligible.

En canvi, es confirma la relació negativa existent entre el valor i el volum de les avaluacions realitzades pels usuaris, ja detectada en estudis recents (Cai et al., 2019). Aquest resultat suggereix que la quantitat de comentaris rebuts per un allotjament és més aviat una indicació de la demanda (ja que els llistats més econòmics solen rebre més reserves i més ressenyes) que no pas un senyal de qualitat (Wang i Nicolau, 2017).

També es posa de manifest que el volum de valoracions que fan els clients interactua amb el signe d'aquestes valoracions, un resultat que complementa l'obtingut per Teubner et al. (2017), que observaren que l'impacte negatiu del volum de revisions era més intens per als allotjaments que obtenien unes puntuacions mitjanes més baixes. Els resultats mostren com, per a cada puntuació, un augment del volum de revisions té un impacte positiu en els preus. Aquesta troballa revela que els usuaris potencials utilitzen eficaçment la informació generada pels hostes anteriors, primer adquirint una percepció inicial mitjançant el valor mitjà atorgat a l'allotjament i posteriorment validant la seva impressió en funció del nombre de valoracions publicades. La seva expectativa envers el valor d'un allotjament és superior quan l'allotjament ha rebut una alta qualificació acompanyada d'un elevat nombre de comentaris. Les estratègies de preus són més efectives, doncs, quan la reputació i l'esforç dels amfitrions es tradueixen en un gran nombre de comentaris i avaluacions excel.lents.

Per la seva part, la competència directa i les estratègies de preus de la competència localitzada a l'entorn proper també afecten la determinació de preus. En els districtes amb més opcions d'allotjament, la proximitat d'allotjaments alternatius en el mercat digital no fa disminuir els preus. Aquest resultat, que no és intuittiu, pot ser una conseqüència de la distribució dels serveis turístics a Barcelona, els quals es concentren desproporcionadament al centre i a les zones d'atracció turística circumdants. Per tant, l'allotjament d'Airbnb en aquests districtes (51,3\% de l'oferta total a la ciutat) té més possibilitats d'atreure visitants, tot i la major densitat de competidors directes. El treball recent d'Önder et al. (2019), examinant l'efecte de la distribució territorial d'hotels i allotjaments d'Airbnb a Tallinn, obté resultats similars. La forta concentració de demanda en aquestes zones impulsa els preus a l'alça, tot i l'elevada densitat de l'oferta d'allotjaments.

Finalment, es posa de manifest l'existència de dependències geogràfiques en la fixació de preus. Les decisions adoptades pels consumidors que ofereixen allotjaments similars situats en un radi de 500 metres de distància serveixen de model de referència en l'estratègia de preus dels usuaris no professionals de la plataforma. L'existència d'una competència intensa i basada en els preus, i d'una experiència i capacitats empresarials relativament menors induirien l'aparició d'aquestes interaccions territorials (Li et al., 2018).

\section{Conclusions}

Aquest treball de recerca ha estat motivat per l'escassetat d'estudis previs sobre les estratègies de preus desenvolupades pels usuaris d'Airbnb que ofereixen un ús total o compartit de les seves llars als seus homòlegs, i ho fan de forma informal, no comercial i col-laborativa. La formació de preus en aquest mercat bilateral peer-topeer és altament complexa a causa de l'àmplia dimensió i diversitat de l'oferta existent i de la presència creixent d'operadors professionals. L'èxit de la plataforma i la seva ràpida expansió han despertat l'interès d'empreses i intermediaris professionals, que la utilitzen per ampliar les seves oportunitats de negoci i optimitzar la rendibilitat de la seva cartera immobiliària. Com a resultat, aquest mercat digital cada cop més allotja activitats mercantils que no s'ajusten necessàriament al model de consum col·laboratiu (Ke, 2017).

L'anàlisi dels mecanismes que intervenen en la fixació de preus ens mostra com les decisions es basen en els atributs intrínsecs i extrínsecs de la proposta de valor. Més específicament, ens proporciona evidències que, tot i que les decisions de consum col-laboratiu són guiades tant pels components utilitaristes com per la reputació de la proposta de valor, la cerca de funcionalitat domina les valoracions dels allotjaments realitzades pels 
consumidors. De la mateixa manera, ens posa de manifest que el capital reputacional de la proposta de valor (col/lectivament construit pels consumidors) es veu afectat per un efecte d'impuls de la demanda derivat de la interacció entre el valor de les avaluacions dels hostes i el seu volum.

La valoració dels allotjaments per part dels consumidors en funció dels atributs intrínsecs i extrínsecs té implicacions importants per als usuaris que proporcionen l'oferta residencial i han de formular estratègies de preus. Prèviament a la publicació de les seves propietats al mercat digital, els amfitrions ocasionals han de saber comprendre adequadament quins són els atributs que generen més valor als consumidors. Com que Airbnb ha configurat un mercat digital bilateral amb alta diversitat d'oferta i competència intensa, aquest procés d'avaluació dels diferents atributs que aporten utilitat esdevé crucial perquè els actors implicats en l'economia purament collaborativa desenvolupin una estratègia de preus que sigui sostenible.

Els resultats obtinguts també són útils per als gestors polítics en la mesura que posen de relleu les interdependències que existeixen en la formació de preus entre els intercanvis d'igual a igual i els mercats convencionals que operen a la mateixa àrea geogràfica. En particular, es posen de manifest les dificultats dels amfitrions no professionals de diferenciar el valor de la seva oferta en un mercat digital altament competitiu. Als districtes amb més concentració d'atraccions turístiques, aquestes interdependències poden agreujar els efectes negatius d'una alta densitat d'oferta d'allotjament d'usos vacacionals en el mercat de lloguer residencial.

\section{Referències bibliogràfiques}

ABRATE, G.; VIGLIA, G. (2016), «Strategic and tactical price decisions in hotel revenue management». Tourism Management (vol. 55, pàg. 123-132). DOl: https://doi.org/10.1016/j.tourman.2016.02.006

AIRBNB (2019). "Get the data - Inside Airbnb: Adding data to the debate» [en línia]. [Consulta: 9 de setembre de 2019]. Disponible a: http://insideairbnb.com/get-the-data.html

AIRBNB. (2020). «Fast facts». Airbnb Newsroom» [en línia] [Consulta: 11 de juny de 2020]. Disponible a: https:// news.airbnb.com/fast-facts/

ALBA, J. W.; HUTCHINSON, J. W.; HUTCHISON, J. (1987). «Dimensions of consumer expertise». Journal of Consumer Research (vol. 13, núm. 4, pàg. 411-454). DOI https://doi.org/10.1086/209080

BECERRA, M.; SANTALÓ, J.; SILVA, R. (2013). «Being better vs. being different: Differentiation, competition, and pricing strategies in the Spanish hotel industry». Tourism Management (vol. 34, pàg. 71-79). DOI https://doi. org/10.1016/j.tourman.2012.03.014

BENÍTEZ-AURIOLES, B. (2018). «Why are flexible booking policies priced negatively?». Tourism Management (vol. 67, pàg. 312-325). DOl: https://doi.org/10.1016/j.tourman.2018.02.008

CAI, Y.; ZHOU, Y.; MA, J.; SCOTT, N. (2019). «Price determinants of Airbnb listings: Evidence from Hong Kong». Tourism Analysis (vol. 24, núm. 2, pàg. 227-242). DOI: https://doi.org/10.3727/108354219X15525055915554

CHEN, Y.; XIE, K. L. (2017). "Consumer valuation of Airbnb listings: A hedonic pricing approach». International Journal of Contemporary Hospitality Management (vol. 29, núm. 9, pàg. 2405-2424). DOl: https://doi. org/10.1108/lJCHM-10-2016-0606

CHOI, H. S.; KO, M.S.; MEDLIN, D.; CHEN, C. (2018). «The effect of intrinsic and extrinsic quality cues of digital video games on sales: An empirical investigation». Decision Support Systems (vol. 106, pàg. 86-96). DOI: https://doi.org/10.1016/j.dss.2017.12.005

CUI, L.; LUI, H-K.; GUO, X. (2012). «The effect of online consumer reviews on new product sales». International Journal of Electronic Commerce (vol. 17, núm. 1, pàg. 39-57). DOl: https://doi.org/10.2753/JEC10864415170102

DELLAERT, B. G. C. (2019). «The consumer production journey: Marketing to consumers as co-producers in the sharing economy». Journal of the Academy of Marketing Science (vol. 47, núm. 2, pàg. 238-254). DOI: https:// doi.org/10.1007/s11747-018-0607-4

DEVLIN, J. F. (2011). «Evaluative cues and services: The effect of consumer knowledge». Journal of Marketing Management (vol. 27, núm. 13/14, pàg. 1366-1377). DOl: https://doi.org/10.1080/0267257X.2011.624533 
DIALLO, M.F.; SECK, A.M. (2018). «How store service quality affects attitude toward store brands in emerging countries: Effects of brand cues and the cultural context». Journal of Business Research (vol. 86, pàg. 311-320). DOI: https://doi.org/10.1016/j.jbusres.2017.08.017

DIMOKA, A.; HONG, Y.; PAVLOU, P. A. (2012). «On product uncertainty in online markets: Theory and evidence». MIS Quarterly (vol. 36, núm. 2, pàg. 395-426). DOI: https://doi.org/10.2307/41703461

EISENMANN, T.; PARKER, G.; Van ALSTYNE, M. (2006). «Strategies for two-sided markets». Harvard Business Review (vol. 84, núm. 10, pàg. 92-101).

ERT, E.; FLEISCHER, A.; MAGEN, N. (2016). «Trust and reputation in the sharing economy: The role of personal photos in Airbnb». Tourism Management (vol. 55, pàg. 62-73). DOI: https://doi.org/10.1016/j.tourman.2016.01.013

ETZION, H.; AWAD, N. (2007). «Pump up the volume? Examining the relationship between number of online reviews and sales: is more necessarily better?». ICIS 2007 Proceedings - Twenty Eighth International Conference on Information Systems.

EUROMONITOR INTERNATIONAL (2019). Top 100 City Destinations: 2019 Edition. Euromonitor International: London.

FLEISCHER, A. (2012). «A room with a view - A valuation of the Mediterranean Sea view». Tourism Management (vol. 33, núm. 3, pàg. 598-602). DOI: https://doi.org/10.1016/j.tourman.2011.06.016

GIBBS, C.; GUTTENTAG, D.; GRETZEL, U.; MORTON, J.; GOOWILL, A. (2018). «Pricing in the sharing economy: A hedonic pricing model applied to Airbnb listings». Journal of Travel and Tourism Marketing (vol. 35, núm. 1, pàg. 46-56). DOI: https://doi.org/10.1080/10548408.2017.1308292

GUTTENTAG, D. (2019). «Progress on Airbnb: A literature review». Journal of Hospitality and Tourism Technology (vol. 10, núm. 3, pàg. 233-263). DOl: https://doi.org/10.1108/JHTT-08-2018-0075

$\mathrm{HABIBI}$, M. R. (2019). «The progression and impact of the sharing economy: A preface». Journal of Marketing Theory and Practice (vol. 27, núm. 4, pàg. 349-354). DOl: https://doi.org/10.1080/10696679.2019.1644959

HENTEN, A. H.; WINDEKILDE, M. (2016). «Transaction costs and the sharing economy». Info (vol. 18, núm. 1, pàg. 1-15). DOI: https://doi.org/10.1108/info-09-2015-0044

KAKAR, V.; VOETZ, J.; WU, J; FRANCO, J. (2018). «The visible host: Does race guide Airbnb rental rates in San Francisco?». Journal of Housing Economics (vol. 40, pàg. 25-40). DOl: https://doi.org/10.1016/j. jhe.2017.08.001

KAVADIAS, S.; LADAS, K.; LOCH, C. (2016). "The transformative business model: How to tell if you have one». Harvard Business Review (vol. 94, núm. 10, pàg. 90-98).

KE, Q. (2017). «Sharing means renting? An entire-marketplace analysis of Airbnb». WebSci 2017 - Proceedings of the 2017 ACM Web Science Conference (pàg. 131-139). Troy, NY: Association for Computing Machinery. DOI: https://doi.org/10.1145/3091478.3091504

KLEIN, B.; LEFFER, K. B. (1981). «The role of market forces in assuring contractual performance». Journal of Political Economy (vol. 89, núm. 4, pàg. 615-641). DOl: https://doi.org/10.1086/260996

KOSTYRA, D.S.; REINER, J.; NATTER, M.; KLAPPER, D. (2016). «Decomposing the effects of online customer reviews on brand, price, and product attributes». International Journal of Research in Marketing (vol. 33, núm. 1, pàg. 11-26). DOI: https://doi.org/10.1016/j.jijesmar.2014.12.004

KUMAR, V.; REINARTZ, W. (2016). «Creating enduring customer value». Journal of Marketing (vol. 80, núm. 6, pàg. 36-68). DOI: https://doi.org/10.1509/jm.15.0414

KWOK, L.; XIE, K. L. (2019). «Pricing strategies on Airbnb: Are multi-unit hosts revenue pros?». International Journal of Hospitality Management (vol. 82, pàg. 252-259). DOl: https://doi.org/10.1016/j.jijhm.2018.09.013

LANCASTER, K. J. (1966). «A new approach to consumer theory». Journal of Political Economy (vol. 74, núm. 2, pàg. 132-157). DOl: https://doi.org/10.1086/259131

LLADÓS-MASLLORENS, J.; MESEGUER-ARTOLA, A.; RODRÍGUEZ-ARDURA, I. (2020). «Understanding peerto-peer, two-sided digital marketplaces: Pricing lessons from Airbnb in Barcelona». Sustainability (vol. 12, núm. 13, pàg. 5229). DOI: https://doi.org/10.3390/su12135229 
LI, J.; MORENO, A.; ZHANG, D. J. (2016). «Pros vs Joes: agent pricing behavior in the sharing economy». Ross School of Business at the University of Michigan Research Paper Series Journal, Ann Arbor, Michigan. DOl: https://doi.org/10.2139/ssrn.2708279

LI, J.; MORENO, A.; ZHANG, D. J. (2019). «Agent Pricing in the sharing economy: Evidence from Airbnb». A HU, M. (ed.), Sharing economy. Ann Arbor, Ml: Springer (pàg. 485-503). DOl: https://doi.org/10.1007/978-3-03001863-4_20

LIANG, L. J.; CHOI, H. C.; JOPPE, M. (2018). «Understanding repurchase intention of Airbnb consumers: Perceived authenticity, electronic word-of-mouth, and price sensitivity». Journal of Travel and Tourism Marketing (vol. 35, núm. 1, pàg. 73-89). DOI: https://doi.org/10.1080/10548408.2016.1224750

MASLOWSKA, E.; MALTHOUSE, E. C.; VISWANATHAN, V. (2017). "Do customer reviews drive purchase decisions? The moderating roles of review exposure and price». Decision Support Systems (vol. 98, pàg. 1-9). DOI: https://doi.org/10.1016/j.dss.2017.03.010

MESEGUER-ARTOLA, A.; RODRÍGUEZ-ARDURA, I. (2015). "Learning from customer interaction: How merchants create price-level propositions for experience goods in hybrid market environments». Computers and Human Behaviour (vol. 51, part B, pàg. 952-959). DOl: https://doi.org/10.1016/j.chb.2014.10.013

NEWLANDS, G.; LUTZ, C.; FIESELER, C. (2018). "Navigating peer-to-peer pricing in the sharing economy». SSRN Electronic Journal (núm. 3116954). DOI: https://doi.org/10.2139/ssrn.3116954

OLSON, J. C.; JACOBY, J. (1972). "Cue utilization in the quality perception process». A: Venkatesan, M. (ed.), Proceedings of the Third Annual Conference of the Association for Consumer Research. Chicago, IL: Association for Consumer Research.

ÖNDER, I., WEISMAYER, C.; GUNTER, U. (2019). «Spatial price dependencies between the traditional accommodation sector and the sharing economy». Tourism Economics (vol. 25, núm. 8, pàg. 1150-1166). DOI: https:// doi.org/10.1177/1354816618805860

PEREZ-SANCHEZ, V. R.; SERRANO-ESTRADA, L.; MARTÍ, P.; MORA-GARCIA, R. T. (2018). «The what, where and why of Airbnb price determinants». Sustainability (vol. 10, núm. 12, pàg. 4596). DOl: https://doi. org/10.3390/su10124596

RAMASWAMY, V.; OZCAN, K. (2018). «What is co-creation? An interactional creation framework and its implications for value creation». Journal of Business Research (vol. 84, pàg. 196-205). DOl: https://doi.org/10.1016/j. jbusres.2017.11.027

RAO, V. R. (1984). «Pricing research in marketing: The state of the art». Journal of Business (vol. 57, núm. 1, pàg. S39-S60). DOI: https://doi.org/10.1086/296235

RICHARDSON, P. S.; DICK, A. S.; JAIN, A. K. (1994). «Extrinsic and intrinsic cue effects on perceptions of store brand quality». Journal of Marketing (vol. 58, núm. 4, pàg. 28-36). DOl: https://doi.org/10.1177/002224299405800403

ROSEN, S. (1974). «Hedonic prices and implicit markets: Product differs». Journal of Political Economy (vol. 82, núm. 1, pàg. 34-55). DOI: https://doi.org/10.1086/260169

SCHAMEL, G. (2012). «Weekend vs. midweek stays: modelling hotel room rates in a small market». International Journal of Hospitality Management (vol. 31, núm. 4, pàg. 1113-1118). DOl: https://doi.org/10.1016/j. ijhm.2012.01.008

SHAPIRO, C. (1983). Premiums for high quality products as returns to reputations. Quarterly Journal of Economics (vol. 98, núm. 4, pàg. 659-680). DOl: https://doi.org/10.2307/1881782

SOPRANZETTI, B. J. (2010). «Hedonic regression analysis in real estate markets: A primer» A: Handbook of Quantitative Finance and Risk Management (pàg. 1201-1207). New York, NY: Springer. DOI: https://doi. org/10.1007/978-0-387-77117-5_78

SUNDARARAJAN, A. (2016). The sharing economy: The end of employment and the rise of crowd-based capitalism. Cambridge, MA: MIT Press.

TEUBNER, T.; HAWLITSCHEK, F.; DANN, D. (2017). «Price determinants on Airbnb: How reputation pays off in the sharing economy». Journal of Self-Governance and Management Economics (vol. 5, núm. 4, pàg. 53-80). DOI: https://doi.org/10.22381/JSME5420173 
WANG, D.; NICOLAU, J. L. (2017). «Price determinants of sharing economy based accommodation rental: A study of listings from 33 cities on Airbnb.com». International Journal of Hospitality Management (vol. 62, pàg. 120-131). DOl: https://doi.org/10.1016/j.ijhm.2016.12.007

YE, Q.; LI, H.; WANG, Z.; LAW, R. (2014). «The influence of hotel price on perceived service quality and value in e-tourism: An empirical investigation based on online traveller reviews». Journal of Hospitality and Tourism Research (vol. 38, núm. 1, pàg. 23-39). DOl: https://doi.org/10.1177/1096348012442540

ZIETZ, J.; ZIETZ, E. N.; SIRMANS, G. S. (2008). «Determinants of house prices: A quantile regression approach». Journal of Real Estate Finance and Economics (vol. 37, núm. 4, pàg. 317-333). DOl: https://doi.org/10.1007/ s11146-007-9053-7

Citació recomanada: LLADÓS-MASLLORENS, Josep; MESEGUER-ARTOLA, Antoni; RODRÍGUEZARDURA, Inma. Fixació de preus en mercats digitals bilaterals entre iguals: el cas d'Airbnb a Barcelona. Oikonomics [en línia]. Novembre 2020, n. 14, pp. 1-12. ISSN: 2339-9546. DOI: https://doi.org/10.7238/o. $\mathrm{n} 14.2015$ 


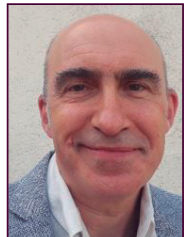

\section{Josep Lladós-Masllorens}

jlladosm@uoc.edu

\section{Universitat Oberta de Catalunya}

Llicenciat i doctor en Ciències Econòmiques i Empresarials per la Universitat de Barcelona, professor agregat dels Estudis d'Economia i Empresa de la UOC, i investigador del grup de recerca DigiBiz (http://transfer.rdi.uoc.edu/es/grupo/digital-businessresearch-group). La seva àrea de coneixement és l'economia aplicada i focalitza la seva activitat de recerca principalment en els àmbits de l'economia internacional, la geografia econòmica i els mercats digitals.

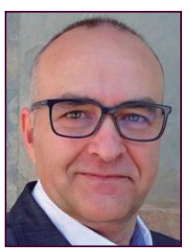

\section{Antoni Meseguer-Artola} ameseguer@uoc.edu Universitat Oberta de Catalunya

Llicenciat en Matemàtiques (UB) i doctor en Ciències Econòmiques i Empresarials (UAB), professor agregat de Mètodes Quantitatius dels Estudis d'Economia i Empresa de la UOC, director del programa de doctorat en ADE (UOC) i membre del grup de recerca Digital Business (DigiBiz). La seva activitat de recerca es focalitza actualment en l'estudi del comportament dels usuaris en entorns virtuals immersius, en l'educació en línia i en l'economia collaborativa.

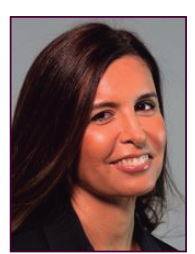

\section{Inma Rodríguez-Ardura}

irodriguez@uoc.edu Universitat Oberta de Catalunya

Doctora en Ciències Econòmiques i Empresarials per la Universitat de Barcelona, professora agregada de Màrqueting dels Estudis d'Economia i Empresa de la UOC i directora del grup de recerca DigiBiz (Digital Business Research Group). Ha estat visiting fellow de la Universitat d'Oxford, visiting professor de Babson College, Boston, i part-time lecturer de la Miami Herbert Business School. La seva recerca se situa en els camps del màrqueting digital, el comerç electrònic i les experiències immersives dels consumidors connectats

Els textos publicats en aquesta revista estan subjectes -llevat que s'indiqui el contrari- a una llicència de Reconeixement 4.0 Internacional de Creative Commons. Podeu copiar-los, distribuir-los, comunicar-los públicament i fer-ne obres derivades sempre que reconegueu els crèdits de les obres (autoria, nom de la revista, institució editora) de la manera especificada pels autors o per la revista. La llicència completa es pot consultar a https://creativecommons.org/licenses/by/4.0/deed.ca.

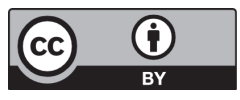

